\title{
Epidemiology and associations with climatic conditions of Mycoplasma pneumoniae and Chlamydophila pneumoniae infections among Chinese children hospitalized with acute respiratory infections
}

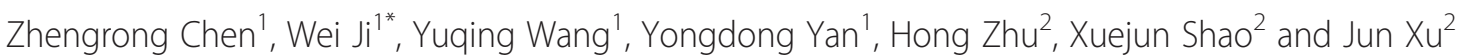

\begin{abstract}
Background: The incidence of severe acute respiratory tract infections in children caused by Mycoplasma pneumoniae (syn. Schizoplasma pneumoniae) and Chlamydophila pneumoniae (formerly Chlamydia pneumoniae) varies greatly from year to year and place to place around the world. This study investigated the epidemiology of M. pneumoniae and C. pneumoniae infections among children hospitalized with acute respiratory infections in Suzhou, China in the year 2006, and associations between incidence rates and climatic conditions.

Methods: Nasopharyngeal aspirates obtained from 1598 patients (aged 26.4 28.3 months; range, 1 month to 13 years) were analyzed with real-time PCR and ELISA. Meteorological data were obtained from the weather bureau.

Results: About $18.5 \%$ of patients were infected with M. pneumoniae and, C. pneumoniae, or both. Isolated M. pneumoniae infection was positively correlated with increasing age $\left(X^{2}=34.76, P<0.0001\right)$. Incidence of $M$. pneumoniae infection was seasonal with a peak in summer $(P<0.0001)$ and minimum in winter $(P=0.0001)$, whereas $C$. pneumoniae infection was low only in autumn $(P=0.02)$. Monthly mean temperature was strongly correlated with the incidence of $M$. pneumoniae infection $(r=0.825, P=0.001)$.
\end{abstract}

Conclusions: M. pneumoniae and C. pneumoniae are important infectious agents in hospitalized children with acute respiratory tract infections. M. pneumoniae infection showed a strong direct correlation with environmental temperature.

Keywords: Acute respiratory tract infection, Mycoplasma pneumoniae, Chlamydophila pneumoniae, Epidemiology, China

\section{Introduction}

The atypical pathogens Mycoplasma pneumoniae (syn. Schizoplasma pneumoniae), Chlamydophila pneumoniae (Chlamydia pneumoniae), and Legionella pneumophila cause mild, moderate, or severe acute respiratory tract infections (ARTIs) in children, although Legionella pneumophila infection is more common in adults. These infections occur worldwide [1-3]. Cyclical outbreaks of

\footnotetext{
*Correspondence: szdxjiwei@163.com

'Department of Respiratory Disease, Children's Hospital Affiliated to Soochow University, No. 303 JingDe Road, Suzhou, Jiangsu Province 215003, China Full list of author information is available at the end of the article
}

M. pneumoniae infections can be expected on average every 3-7 years, but at any given time may account for as many as $40 \%$ of community-acquired pneumonia cases [3]. The prevalence of C. pneumoniae in children with ARTIs varies from 0 to $44 \%$ [4].

Studies of possible associations between the epidemiology of atypical pathogens and meteorological conditions (e.g., temperature, humidity, rainfall, amount of solar radiation and wind velocity) are few. However, it was recently reported that the community incidence of pneumonia due to $M$. pneumoniae increased weekly by $16.9 \%$ for every $1^{\circ} \mathrm{C}$ increase in the average temperature,

\section{() Biomed Central}


and by $4.1 \%$ for every $1 \%$ increase in relative humidity [5]. Community-acquired M. pneumoniae or C. pneumoniae infections affect mainly preschool- and school-aged children and young adults. Few studies have reported the frequency of $M$. pneumoniae and C. pneumoniae infections in infants [6].

Clinically it is difficult to distinguish M. pneumoniae from C. pneumoniae infections and hence laboratory tests are essential in identifying these pathogens. Serological detections, although commonly used, are complicated by false negative results in the early acute phase of infection, and the difficulty in obtaining convalescent serum during hospital stays of one week or less. Polymerase chain reaction (PCR) is suitable for rapid diagnosis of these infections, even when the colonization rate is only $1-2 \%$ of the population [7-9]. Combining both PCR and serology seems to be a more reliable diagnostic approach.

The incidence rate of childhood ARTIs due to these pathogens is very different from one country to another [2-6]. Our purpose was to use PCR to identify and determine the percentage of ARTIs that were due to $M$. pneumoniae and C. pneumoniae, especially in infants, and investigate the relatedness between their epidemiology and meteorological conditions in Suzhou, Jiangsu Province, China. In addition we compared the clinical characteristics of $M$. pneumoniae and C. pneumoniae infections, host immune state, radiographic appearance, and tidal breathing measurements.

\section{Materials and methods Study population}

From 1 January 2006 to 31 December 2006, 1598 consecutive children with ARTIs admitted to Children's Hospital affiliated with Soochow University were enrolled and evaluated prospectively. These children were hospitalized because of prolonged fever ( $>3 \mathrm{~d}$ ), severe symptoms of cough, wheeze, tachypnea, and chest retractions. The clinical outcome and diagnosis for all children were obtained after discharge from the hospital. The discharge diagnosis was based on standard clinical criteria made by attending physicians. Upper respiratory tract infection was diagnosed if a child had nasal obstruction, nasal discharge, fever, or sore throat. Lower respiratory tract infection was diagnosed when wheeze, tachypnea, chest retractions, abnormal auscultatory findings, and radiologic evidence of a lower respiratory tract infection were present. Children were excluded from the study if they had proven chronic lung disease, immunodeficiency, congenital heart disease, or bronchopulmonary dysplasia. The Institutional Review Boards of Suzhou University approved the study protocol, and the parents or legal guardians of each child gave informed written consent.

\section{Methods}

\section{Sample collection}

Nasopharyngeal aspirate (NPA) samples were obtained from each patient within 24 hours of admission using a sterile plastic catheter introduced into the lower part of the pharynx via the nasal cavity. The samples were immediately transported to the Laboratory of Molecular Biology of our hospital for detection of $M$. pneumoniae and $C$. pneumoniae using PCR. Seven common respiratory virus (respiratory syncytial virus, influenza $A$ and $B$, parainfluenza 1, 2, 3 and adenovirus ) using direct immunofluorescence and human metapneumovirus using RT-PCR described previously [10]. Blood samples were also obtained at admission and immediately sent to the Department of Biochemical Laboratory for routine blood, C-reactive protein, humoral and cell immunity, and alanine transaminase tests.

\section{DNA extraction}

Each NPA sample was diluted in $2 \mathrm{~mL}$ of normal saline before centrifugation at $500 \times g$ for 10 minutes. The resultant cell pellet was resuspended and then centrifuged at 12 $000 \times g$ for 5 minutes, followed by extraction of DNA from a 400- $\mu \mathrm{L}$ sample using DNA-EZ Reagents (Sangon Biotech, USA) in accordance with the manufacturer's instructions. A final $200 \mu \mathrm{L}$ of DNA was eluted and divided into 2 aliquots for PCR and stored at $-20^{\circ} \mathrm{C}$.

\section{Detection of M. pneumoniae gene by real-time PCR}

Real-time PCR was performed to identify the P1 adhesion protein gene of $M$. pneumoniae, as described previously [11]. The forward and reverse primers were 5'-CCA ACC AAA CAA CAA CGT TCA-3' and 5'-ACC TTG ACT GGA GGC CGT TA-3, respectively, and the probe sequence was 5-TCA ACT CGA ATA ACG GTG ACT TCT TAC CAC TG-3'. The fluorescent reporter dye at the 5 ' end was 6-carboxyfluorescein (FAM) and the quencher at the 3' end was 6-carboxytetramethylrhodamine (TAMRA). The PCR reactions consisted of a $21-\mu \mathrm{L}$ PCR mast mixture (Shenyou Biotechnology, Shanghai, China) including primers and probes combined with $3 \mu \mathrm{L}$ of the sample DNA and 1 U GoTaq DNA Polymerase (Promgea, Wisconsin, USA). Real-time PCR was performed using an iCycler iQ5 real-time PCR detection system (Bio-Rad, Hercules, CA, USA) and cycling conditions were: $2 \mathrm{~min}$ at $37^{\circ} \mathrm{C} ; 10 \mathrm{~min}$ at $94^{\circ} \mathrm{C}$, and 40 cycles of $10 \mathrm{~s}$ at $94^{\circ} \mathrm{C}, 30 \mathrm{~s}$ at $55^{\circ} \mathrm{C}$, and $40 \mathrm{~s}$ at $72^{\circ} \mathrm{C}$.

Quantification curves were plotted using several concentrations of control plasmids containing the target gene.

\section{Detection of C. pneumoniae gene by nested-PCR}

A different aliquot of extracted DNA from the NPA sample was used for detecting the gene of the major outer membrane protein of $C$. pneumoniae by nested 
touchdown PCR, as described previously [12]. The external and internal primers were: Cpex-F 5'TTA CAA GCC TTG CCT GTA GG-3'; Cpex-R 5'-GCG ATC CCA AAT GTT TAA GGC-3'; Cpin-F 5'-TTA TTA ATT GAT GGT ACA AT A-3'; and Cpin-R 5'ATC TAC GGC AGT AGT ATA GTT-3'. Amplifications were performed in a thermal cycler (GeneAmp PCR System 9600, Applied Biosystems). For the first amplification, $0.4 \mu \mathrm{M}$ of each CPex-F and Cpex-R primer and $2 \mathrm{U}$ GoTaq DNA polymerase (Promgea, Madison, WI, USA) were included in these touchdown PCR reactions. The annealing temperature was lowered $1^{\circ} \mathrm{C}$ every 2 cycles, from $65^{\circ} \mathrm{C}$ until touching down at $55^{\circ} \mathrm{C}$, at which temperature 20 more cycles were performed. The denaturation and extension temperature were constant at $94^{\circ} \mathrm{C}$ and $72^{\circ} \mathrm{C}$, respectively. One microliter of the products of the first round of amplification by external primers were added into the PCR reactions of the second round amplification using internal primers. The second PCR cycling conditions were: $2 \mathrm{~min}$ at $95^{\circ} \mathrm{C}$; and 30 cycles of $1 \mathrm{~min}$ at $94^{\circ} \mathrm{C}, 1 \mathrm{~min}$ at $50^{\circ} \mathrm{C}$, and $1 \mathrm{~min}$ at $72^{\circ} \mathrm{C}$. The nested PCR products were separated via $1.5 \%$ agarose gel electrophoresis and visualized using ethidium bromide staining.

\section{Serology testing for M. pneumoniae and C. pneumoniae}

The presence of specific IgM and IgG antibodies against $M$. pneumoniae were investigated in serum samples of patients using a commercial ELISA kit (Serion ELISA classic $M$. pneumoniae IgG/IgM, Institute Virion\Serion, Germany). IgA and IgG antibodies against C. pneumoniae were detected with Serion ELISA classic C. pneumoniae IgA/IgG Kits. Evidence of acute $M$. pneumoniae infection was defined as either a single positive serum IgM (cutoff $13 \mathrm{U} / \mathrm{mL}$ ) or a 4-fold increase in IgG in convalescent serum obtained a week after admission. Acute C. pneumoniae infection was defined as either a single positive serum IgA (cutoff $3 \mathrm{U} / \mathrm{mL}$ ) or a 4-fold increase in IgG in convalescent serum.

\section{Diagnostic criteria for M. pneumoniae and C. pneumoniae acute infection}

Acute infection due to $M$. pneumoniae or C. pneumoniae was confirmed when any of the following was determined: NPA samples proved positive via PCR, serum samples positive for IgM or IgA, respectively, or IgG increasing 4-fold from the acute to the convalescent phases.

\section{Tidal breathing measurements}

Measurements of tidal breathing in most infants were performed during natural and quiet sleep as assessed by behavioral criteria [13]. Tidal breathing flow-volume loops were obtained and analyzed with a commercially available pediatric pulmonary function device (ECO Medics, V'max 26, Switzerland). Tidal breathing measurements included flow and volume signals, and were assessed by professional staff. Lung function was graded as normal, mild, moderate, severe, or extremely severe according to three-component score system which could reflect underlying obstructive airways disease $[14,15]$ as shown in Table 1.

\section{Meteorological data}

The primary investigator obtained data regarding monthly mean temperatures, relative humidity, rainfall, solar radiation, and mean wind velocity from the local weather bureau for lat $31.19^{\circ} \mathrm{N}$, long $120.37^{\circ} \mathrm{E}$. Suzhou has a subtropical climate and the monthly data for meteorological variables were shown in Figure 1.

\section{Statistical analyses}

Categorical data were analyzed using the CochranMantel-Haenszel statistic or the chi-squared $\left(x^{2}\right)$ or Fisher's exact tests. The continuous variables were compared using analysis of variance (ANOVA). The Kruskal-Wallace test was used if the data were abnormal in distribution or nonparametric. The associations between meteorological conditions and the prevalence of the 2 pathogens were evaluated using Spearman's rank correlations. A $P$-value $<0.05$ was considered statistically significant. All analyses were performed using the Statistical Package for SAS for windows, version 8.2 (SAS, USA).

\section{Results}

\section{Epidemiology}

Of the 1598 children admitted to our hospital for ARTIs, 957 (59.9\%) were boys, and the ratio of boys to girls was $1.5: 1$. The mean age was $26.4 \pm 28.3$ months (range: 1 month to 13 years). Of all the children, 817 (51.1\%) were aged < one year, $616(38.5 \%)$ were $1-5$ years, and $165(10.3 \%)$ were $>5$ years old.

Twenty-three cases of M. pneumoniae infection and 6 cases of $C$. pneumoniae infection had co-infections with other viruses (data not shown), and cases of M. pneumoniae or C. pneumoniae coinfection with viruses were excluded in this study. ARTIs were caused by $M$. pneumoniae or $C$. pneumoniae in 295 (18.5\%) of the patients. The mean age

Table 1 Three-component score system for assessing tidal lung function

\begin{tabular}{lllll}
\hline Parameters & \multicolumn{4}{c}{ Scores } \\
\cline { 2 - 5 } & $\mathbf{0}$ & $\mathbf{1}$ & $\mathbf{2}$ & $\mathbf{3}$ \\
\hline PTEF/t-PTEF(mL/s $\left.{ }^{2}\right)$ & $<3$ & $3-6$ & $7-10$ & $>10$ \\
25TEF/PTEF (\%) & $>80$ & $60-80$ & $40-60$ & $<40$ \\
t-PTEF/t-E (\%) & $>30$ & $20-30$ & $10-20$ & $<10$
\end{tabular}

The score for 5 levels of tidal lung function. Normal: 0 , Mild: $<3$, moderate: 3-5, Severe: $6-7$, Extremely severe: $8-9$. PTEF peak tidal expiratory flow, $t-P T E F$ time to peak tidal expiratory flow, $25 T E F$ tidal expiratory flow at $25 \%$ of tidal volume remaining, $t-E$, expiratory time. 


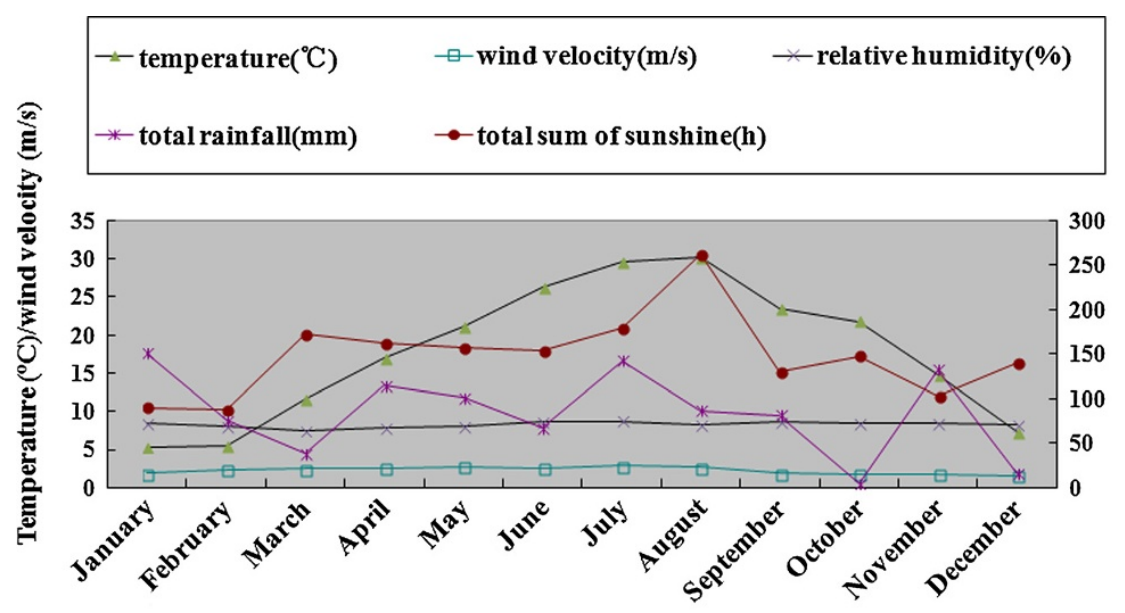

Figure 1 The monthly data for meteorological variables in Suzhou, China.

of these children was $33.1 \pm 36.3$ months. There were 171 boys, and the ratio of boys to girls was 1.4:1. Of the 295 infected with either or both of these pathogens, 199 (12.5\%) were due to $M$. pneumoniae alone (mean age $35.8 \pm 37.3$ months), 81 (5.1\%) were due to C. pneumoniae alone (mean age $27.3 \pm 34.5$ months), and 15 (5.1\%) were co-infected (mean age $28.0 \pm 29.7$ months). The infection rate due to M. pneumoniae only was significantly and positively associated with increasing age $\left(X^{2}=34.76, P<0.0001\right)$. With regard to demographic data, no significant difference in gender or prematurity was found among the 3 etiological groups (Table 2).

\section{Seasonality and correlations with meteorological conditions}

Both $M$. pneumoniae and $C$. pneumoniae infections occurred throughout the year. The M. pneumoniae

Table 2 The prevalence and demographic data of children hospitalized with $M$. pneumoniae and $C$. pneumoniae infection

\begin{tabular}{|c|c|c|c|}
\hline & M. pneumoniae ${ }^{a}$ & C. pneumoniae ${ }^{b}$ & Co-infection $^{c}$ \\
\hline Age & n/total (\%) & n/total (\%) & n/total (\%) \\
\hline$<1$ year & $80 / 817$ (9.8) & 40/817 (4.9) & 8/817 (0.1) \\
\hline 1 to 5 years & $75 / 616(12.2)$ & $30 / 616(4.9)$ & $5 / 616(0.1)$ \\
\hline$>5$ years & $44 / 165(26.7)$ & $11 / 165$ (6.7) & $2 / 165(0.1)$ \\
\hline Total & $199 / 1598$ (12.5) & $81 / 1598(5.1)$ & 15/1598 (0.1) \\
\hline Demographics & n (\%) & n (\%) & n (\%) \\
\hline Total (male) & $116(58.3)$ & $46(56.8)$ & $9(60)$ \\
\hline Prematurity & $12(6.0)$ & $4(4.9)$ & $1(6.7)$ \\
\hline $\begin{array}{c}\text { PICU } \\
\text { Admission }\end{array}$ & $1(0.5)$ & $0(0)$ & $0(0)$ \\
\hline
\end{tabular}

${ }^{a} X_{C M H}^{2}=35.90, P<0.0001 ;{ }^{b} X_{C M H}^{2}=0.98, P=0.614 ;{ }^{c} X_{C M H}^{2}=0.25, P=0.881$ compared among three age groups (Cochran-Mantel-Haenszel Statistic test). Data are presented as number (percentage) or mean \pm SD. infection rate reached a maximum in summer $(P<0.0001)$ and a minimum in winter $(P=0.0001)$, whereas the $C$. pneumoniae infection rate was lowest in autumn $(P=0.02$; Table 3). The peak number of $M$. pneumoniae infections occurred in July $(23.2 \%$ or $32 / 138)$ and were the lowest (4.3\% or 5/117) in December. C. pneumoniae infections were also high in July (12.3\% or $17 / 138$; Figure 2$)$.

Rates of $M$. pneumoniae infection in hospitalized children in Suzhou correlated strongly with monthly mean temperature, and weakly with monthly mean wind velocity (Table 3). There was no significant correlation between meteorological conditions and C. pneumoniae infections.

\section{Clinical manifestations}

There was no significant difference in terms of clinical manifestations among the groups except for fever

Table 3 The seasonality and correlations with climatic conditions of $M$. pneumoniae and C. pneumoniae infection in hospitalized children

\begin{tabular}{lllll}
\hline & \multicolumn{1}{c}{ M. pneumoniae } & \multicolumn{2}{c}{ C. pneumoniae } \\
\hline Seasons & $\mathrm{n}(\%)$ & $\mathrm{n}(\%)$ & \\
Spring (Mar-May) & $43(11.0)$ & $26(6.6)$ & \\
Summer (Jun-Aug) & $86(20.4)^{\mathrm{a}}$ & & $32(7.6)$ & \\
Autumn (Sep-Nov) & $57(13.9)$ & & $15(3.6)^{c}$ & \\
Winter (Dec-Feb) & $28(7.5)^{\mathrm{b}}$ & & $23(6.1)$ & \\
Meteorological conditions & $r$ & $P$ & $r$ & $P$ \\
Temperature ( $\left.{ }^{\circ} \mathrm{C}\right)$ & 0.825 & 0.001 & -0.021 & 0.948 \\
Relative humidity (\%) & 0.527 & 0.782 & 0 & 1.0 \\
Rainfall (mm) & 0.189 & 0.557 & 0.294 & 0.354 \\
Sum of sunshine (h) & 0.392 & 0.208 & 0.070 & 0.829 \\
Wind velocity (m/s) & 0.629 & 0.028 & 0.443 & 0.149 \\
\hline
\end{tabular}

${ }^{\mathrm{a}} P<0.0001 ;{ }^{\mathrm{b}} P=0.0001 ;{ }^{\mathrm{c}} P=0.02$ (prevalence of infections in a particular season compared to the mean prevalence in all other seasons). $r$ Spearman coefficient. 


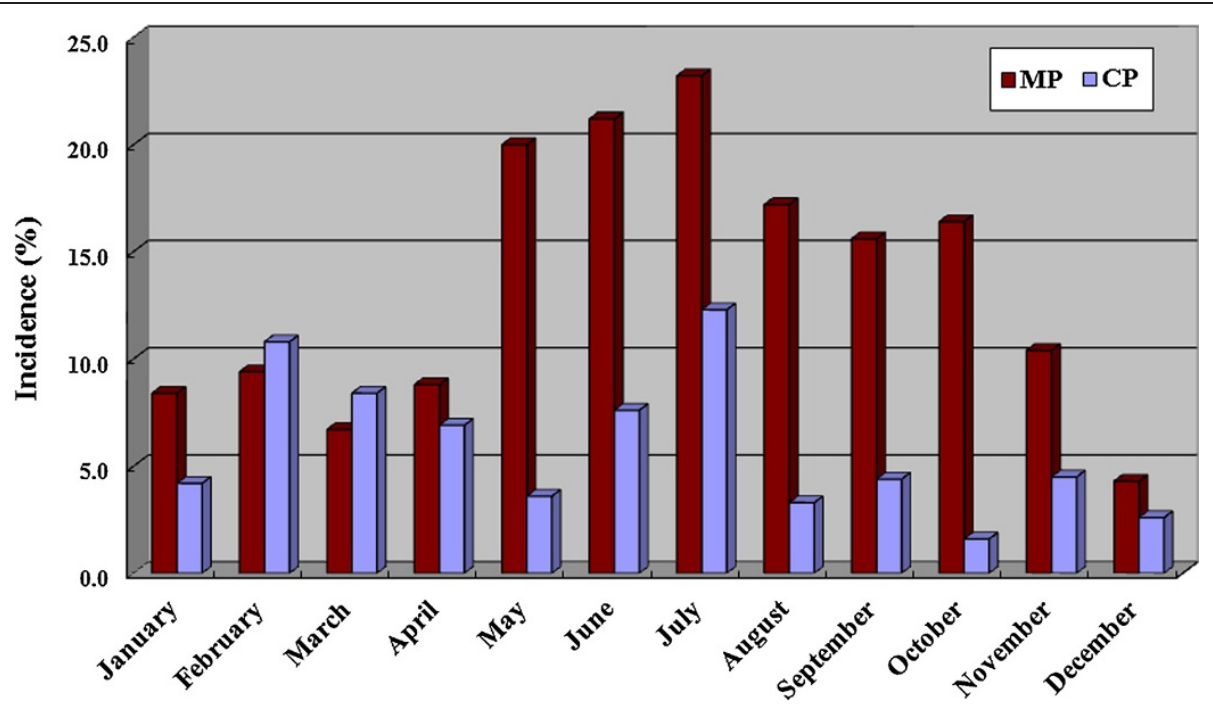

Figure 2 The seasonality of $M$. pneumoniae and C. pneumoniae infections in hospitalized children. MP, M. pneumoniae; $C P$,

C. pneumoniae.

$\left(X^{2}=7.824, P=0.02 ;\right.$ Table 4$)$. Children co-infected with M. pneumoniae and C. pneumoniae were found to have fever more frequently. There were no significant differences in length of hospital stay among the different groups. All patients were cured or improved.

\section{Laboratory findings}

There were no significant differences in laboratory findings (routine blood, C-reactive protein level, humoral and cell immunity, alanine transaminase, radiographic data, and tidal lung function test) among the 3 groups (Table 5).

\section{Discussion}

M. pneumoniae and C. pneumoniae are two common atypical pathogens that cause ARTIs in children worldwide. Infections may be endemic or epidemic. In the present study, the total rate of M. pneumoniae and $C$. pneumoniae infections in hospitalized children with ARTIs in Suzhou, China for the year 2006 was 18.4\% (295/1598), in which $12.5 \%$ and $5.1 \%$ were caused only by $M$. pneumoniae or C. pneumoniae, respectively. In other recent studies in which real-time PCR was used for identification, Defilippi et al. [16] in Genoa, Italy reported an infection rate for M. pneumoniae in children of $11.8 \%$ and in Tokyo, Japan Hamano-Hasegawa et al. [17] found a rate of $14.8 \%$. The rates of M. pneumoniae infection found via real-time PCR tests in Suzhou, China in the years 2007 and 2008 were 5.39\% and 6.36\%, respectively (unpublished results). Hosker et al. [18] reported an epidemic of $M$. pneumoniae infection in Hong Kong with a rate of $15 \%$ to $20 \%$ that occurred from 1986 to 1988, which was similar to our study.
Apparent seasonality of M. pneumoniae infection was observed in this study, with a peak level in summer and the highest rate in July. When the disease is endemic, seasonality may not be a factor, but when it is an epidemic more cases occur in the summer or early autumn $[3,16]$. We observed a similar trend in this study. Onozuka et al. [5] found a strong correlation between temperature and relative humidity and the number of $M$. pneumoniae

Table 4 Clinical manifestations of children hospitalized with $M$. pneumoniae and $C$. pneumoniae infection

\begin{tabular}{|c|c|c|c|}
\hline & M. pneumoniae & C. pneumoniae & Co-infection \\
\hline Hospitalization (d) & $7.5 \pm 2.3$ & $7.3 \pm 1.9$ & $8.1 \pm 2.3$ \\
\hline \multicolumn{4}{|c|}{ Clinical manifestations, n (\%) } \\
\hline Cough & $189(95.0)$ & $75(92.6)$ & $14(93.3)$ \\
\hline Wheezing & $57(28.6)$ & $31(38.3)$ & $6(40)$ \\
\hline Nose running & $40(20.1)$ & $21(25.9)$ & $5(33.3)$ \\
\hline Fever & $114(57.3)^{a}$ & $36(44.4)$ & $12(80)^{b}$ \\
\hline Dyspnea & $12(6.0)$ & $4(4.9)$ & $1(6.7)$ \\
\hline Anorexia & $22(11.1)$ & $7(8.6)$ & $3(20)$ \\
\hline Gastrointestinal & $30(15.1)$ & $17(21.0)$ & $4(26.7)$ \\
\hline Tachypnea & 31 (15.6) & $12(14.8)$ & $3(20)$ \\
\hline Cyanosis & $2(1.0)$ & $0(0)$ & $0(0)$ \\
\hline \multicolumn{4}{|c|}{ Other diagnoses, n (\%) } \\
\hline URTI & $10(5.0)$ & $8(9.9)$ & $1(6.7)$ \\
\hline LRTI & $171(85.9)$ & $66(81.5)$ & $13(86.7)$ \\
\hline $\begin{array}{c}\text { Asthma } \\
\text { exacerbation }\end{array}$ & $18(9.0)$ & 7 (8.6) & $1(6.7)$ \\
\hline
\end{tabular}

${ }^{\mathrm{a}}$ M. pneumoniae group compared with $C$. pneumoniae group, $P=0.05$.

${ }^{b}$ Co-infection group compared with $C$. pneumoniae group, $P=0.011$.

$U R T I$, upper respiratory tract infection; $L R T I$, lower respiratory tract infection. 
Table 5 No significant differences in laboratory findings of children hospitalized with M. pneumonia and C. pneumoniae infection

\begin{tabular}{|c|c|c|c|}
\hline & $\begin{array}{l}\text { M. pneumoniae } \\
(\mathrm{n}=199)\end{array}$ & $\begin{array}{l}\text { C. pneumoniae } \\
(n=81)\end{array}$ & $\begin{array}{l}\text { Co-infection } \\
(n=15)\end{array}$ \\
\hline \multicolumn{4}{|l|}{ Cell immunity } \\
\hline CD3+ (\%) & $63.6 \pm 9.4$ & $65.3 \pm 9.3$ & $61.9 \pm 8.3$ \\
\hline $\mathrm{CD} 3+\mathrm{CD} 4+(\%)$ & $36.8 \pm 8.2$ & $37.5 \pm 8.6$ & $33.9 \pm 4.4$ \\
\hline $\mathrm{CD} 3+\mathrm{CD} 8+(\%)$ & $22.9 \pm 6.7$ & $24.1 \pm 5.7$ & $23.6 \pm 8.1$ \\
\hline CD4/CD8 (\%) & $1.8 \pm 0.8$ & $1.7 \pm 0.7$ & $1.6 \pm 0.6$ \\
\hline CD3-CD19+ (\%) & $26.2 \pm 9.8$ & $26.1 \pm 8.9$ & $29.7 \pm 9.2$ \\
\hline CD3-CD (16+56+) (\%) & $8.8 \pm 5.7$ & $6.6 \pm 3.9$ & $6.8 \pm 2.8$ \\
\hline CD19 + CD23+ (\%) & $6.6 \pm 3.6$ & $6.9 \pm 2.9$ & $7.8 \pm 2.5$ \\
\hline $\mathrm{CD} 4+\mathrm{CD} 25+(\%)$ & $7.4 \pm 3.5$ & $6.0 \pm 3.7$ & $7.0 \pm 2.4$ \\
\hline Chest $X$-rays (LRTI) * & $\mathrm{n}=171$ & $n=66$ & $n=13$ \\
\hline Lobar consolidation (\%) & $23(13.5)$ & $7(10.6)$ & $2(15.4)$ \\
\hline Infiltration/opacities (\%) & $105(61.4)$ & $41(62.1)$ & $8(61.5)$ \\
\hline Hyper aeration (\%) & $16(9.4)$ & $10(15.2)$ & $2(15.4)$ \\
\hline Interstitial lesions (\%) & $59(34.5)$ & $25(37.9)$ & $4(30.8)$ \\
\hline Pleural reaction (\%) & $4(2.3)$ & $0(0)$ & $1(7.7)$ \\
\hline Tidal lung function (LRTI) & $n=82$ & $n=54$ & $n=9$ \\
\hline Normal (0) & $13(15.9)$ & $9(16.7)$ & $1(11.1)$ \\
\hline Mild (1-3) & $22(26.8)$ & $6(11.1)$ & $1(11.1)$ \\
\hline Moderate (4-5) & $23(28.0)$ & $18(33.3)$ & $1(11.1)$ \\
\hline Severe (6-7) & $20(24.3)$ & $17(31.5)$ & $4(44.4)$ \\
\hline Extremely severe (8-9) & $4(4.9)$ & $4(7.4)$ & $2(22.2)$ \\
\hline
\end{tabular}

${ }^{*}$ Chest X-rays and tidal lung function were only performed on children with $L R T I . C D$ cluster of differentiation, $L R T I$ lower respiratory tract infection.

pneumonia cases in hospitalized children younger than 15 years in Japan, while another study in Germany did not show any correlation [19]. However, we presume that climatic conditions in our area are similar to Japan, and different from the northwestern region of Germany where the range of temperatures across the seasons is not as great.

Regarding C. pneumoniae infections, the $6.0 \%$ rate in children with ARTIs found in the present study is similar to the $6.7 \%(4 / 112)$ found in a study performed by Kurz et al. [20] in Vienna, Austria, and lower than the 9.3\% reported by Schmidt et al. [21] for Greifswald, Germany. No seasonality or correlation with climatic conditions was found in our study. Studies conducted in various countries have shown that $M$. pneumoniae and C. pneumoniae infections are most common in schoolaged children, followed by children from 1 to 5 years old, but rare in infants [16,21-24]. In contrast, we found that M. pneumoniae (10.8\%) and C. pneumoniae (5.9\%) infections are also common in infants. The high population density in China, which increases exposure and the chance of infection, may be an important influence in acquiring these infections.
The use of PCR in the present study provided rapid and specific diagnosis of $M$. pneumoniae and $C$. pneumoniae infections. A recent retrospective study comparing the diagnostic value of PCR to the indirect particle agglutination antibody test for M. pneumoniae infection in children from NPA samples found that PCR provided a more rapid diagnosis, particularly in young children $(P=0.003)$, immunocompromised patients $(P=0.019)$, and during the early stage of the disease [25]. When PCR is combined with serological tests the yield increases further [26].

In the present study, the clinical manifestations and laboratory findings did not differ between M. pneumoniae and $C$. pneumoniae. Cough and fever were the most common symptoms. Fever was noticed more frequently in children with co-infection, although co-infection did not increase the severity of clinical manifestations. The rate of wheezing in $M$. pneumoniae or C. pneumoniae infections was higher than that reported by Esposito et al. [27], and the rates of dyspnea and tachypnea were lower. The reason for this may be that the present study included upper respiratory infection, bronchitis, and asthma exacerbation within the definition of ARTIs. 
The $8.8 \%(26 / 295)$ incidence of $M$. pneumoniae or $C$. pneumoniae infections with asthma exacerbation in this study indicates a possible role of infection by these atypical pathogens in asthma exacerbation. Recently, it was reported that in asthma $M$. pneumoniae and $C$. pneumoniae appeared to be involved more with asthma persistence than exacerbation [28].

In previous studies, no significant difference was found between $M$. pneumoniae and C. pneumoniae infections with regard to white blood cell count, C-reactive protein, percentage of neutrophils, platelets, or radiographic data $[16,27,29]$. To the best of our knowledge, this study is the first to analyze the humoral and cell immunity status and tidal lung function of children with M. pneumoniae and C. pneumoniae infections. Although no significant difference in immunity status existed between the patients infected with the two pathogens, some studies showed a depressed humoral and cellular immunity in children with $M$. pneumoniae infection compared to healthy children [30,31]. Because of the difficulty in distinguishing M. pneumoniae infection from C. pneumoniae on the basis of clinical manifestations or laboratory findings, PCR tests are very useful [32].

The limitations of our study include a probable bias, as the study was conducted only in hospitalized children and not outpatients. In addition, a study period of only one year is relatively short to assess the epidemiology of M. pneumoniae and C. pneumoniae infection.

\section{Conclusion}

M. pneumoniae infections in children demonstrated a definite seasonality, a strong correlation with the temperature, and a weak correlation with wind velocity. Consistent with former studies, ours indicates that $M$. pneumoniae and $C$. pneumoniae are important in children with ARTIs who are younger than 5 years old, and especially in infants. Clinical manifestations and laboratory findings were informative, but real-time PCR and nested-PCR provide adequate rapid and specific diagnosis of $M$. pneumoniae and $C$. pneumoniae infections.

\section{Competing interests}

The authors declare that they have no competing interests.

\section{Authors' contributions}

ZC: carried out the molecular genetic studies, participated in the sequence alignment and drafted the manuscript. WJ: design of experiment and drafted the manuscript. YW: drafted the manuscript. YY: design of experiment and drafted the manuscript. $\mathrm{HZ}$ : carried out the molecular genetic studies. XS: carried out the molecular genetic studies, participated in the sequence alignment. JX: carried out the molecular genetic studies, participated in the sequence alignment. All authors read and approved the final manuscript.

\section{Acknowledgments}

The authors thank Dr. Aili Zhang, Department of Respiratory Disease, Municipal Hospital, Suzhou, for data collecting. The authors are also grateful to Dr. Yan Zhu, PhD, Weather Bureau, Suzhou, for providing meteorological data and Jing Zhou, MD, for her help with language editing.

\section{Funding}

This work was supported by the Social Development, Science and Technology Projects of Suzhou (grant number SS0702 to Wei Ji) and the Science and Technology Projects for the Youth of Suzhou (grant number KUQND2011005 to Zhengrong Chen).

\section{Author details}

'Department of Respiratory Disease, Children's Hospital Affiliated to Soochow University, No. 303 JingDe Road, Suzhou, Jiangsu Province 215003, China. ${ }^{2}$ Laboratory of Molecular Biology, Children's Hospital Affiliated to Soochow University, Suzhou, China.

Received: 4 November 2012 Accepted: 20 May 2013

Published: 25 May 2013

\section{References}

1. D'Auria G, Jiménez-Hernández N, Peris-Bondia F, Moya A, Latorre A: Legionella pneumophila pangenome reveals strain-specific virulence factors. BMC Genomics 2010, 11:181.

2. Nir-Paz R, Abutbul A, Moses AE, Block C, Hidalgo-Grass C: Ongoing epidemic of mycoplasma pneumoniae infection in Jerusalem, Israel, 2010 to 2012. Euro Surveill 2012, 17:20095.

3. Waites $\mathrm{K}$ : New concepts of mycoplasma pneumoniae infections in children. Pediatr Pulmonol 2003, 36:267-278.

4. Kumar S, Hammerschlag MR: Acute respiratory infection due to the Chlamydia pneumoniae: current status of diagnostic methods. Infect Dis 2007, 44:568-576.

5. Onozuka D, Hashizume M, Hagihara A: Impact of weather factors on mycoplasma pneumoniae pneumonia. Thorax 2009, 64:507-511.

6. Stuckey-Schrock K, Hayes BL, George CM: Community-acquired pneumonia in children. Am Fam Physician 2012, 86:661-667.

7. Palma SC, Martínez TMA, Salinas SM, Rojas GP: Asymptomatic pharyngeal carriage of mycoplasma pneumoniae in Chilean children. Rev Chilena Infectol 2005, 22:247-250

8. Hyman CL, Roblin PM, Gaydos CA, Quinn TC, Schachter J, Hammerschlag MR: Prevalence of asymptomatic nasopharyngeal carriage of Chlamydia pneumoniae in subjectively healthy adults: assessment by polymerase chain reaction-enzyme immunoassay and culture. Clin Infect Dis 1995, 20:1174-1178.

9. Wolf J, Daley AJ: Microbiological aspects of bacterial lower respiratory tract illness in children: atypical pathogens. Paediatr Respir Rev 2007, 8:212-219

10. Ji W, Wang Y, Chen Z, Shao X, Ji Z, Xu J: Human metapneumovirus in children with acute respiratory tract infections in Suzhou, China 2005-2006. Scand J Infect Dis 2009, 41:735-744

11. Hardegger D, Nadal D, Bossart W, Altwegg M, Dutly F: Rapid detection of mycoplasma pneumoniae in clinical samples by real-time PCR. J Microbiol Methods 2000, 41:45-51.

12. Tong CY, Sillis M: Detection of Chlamydia pneumoniae and Chlamydia psittaci in sputum samples by pcr. J Clin Pathol 1993, 46:313-317.

13. Prechtl HF: The behavioural states of the newborn infant (a review). Brain Res 1974, 76:185-212

14. Lødrup Carlsen KC, Stenzler A, Carlsen KH: Determinants of tidal flow volume loop indices in neonates and children with and without asthma. Pediatr Pulmonol 1997, 24:391-396.

15. Schmalisch G, Wilitzki S, Wauer RR: Differences in tidal breathing between infants with chronic lung diseases and healthy controls. BMC Pediatr 2005, 5:36.

16. Defilippi A, Silvestri M, Tacchella A, Giacchino R, Melioli G, Di Marco E, Cirillo C, Di Pietro P, Rossi GA: Epidemiology and clinical features of mycoplasma pneumoniae infection in children. Respir Med 2008, 102:1762-1768.

17. Hamano-Hasegawa K, Morozumi M, Nakayama E, Chiba N, Murayama SY, Takayanagi R, Iwata S, Sunakawa K, Ubukata K: Comprehensive detection of causative pathogens using real-time PCR to diagnose pediatric community-acquired pneumonia. I Infect Chemother 2008, 14:424-432.

18. Hosker HS, Tam JS, Chain CH, Lai CK: Mycoplasma pneumoniae infection in Hong Kong - clinical and epidemiological features during an epidemic. Respiration 1993, 60:237-240.

19. du Prel JB, Puppe W, Gröndahl B, Knuf M, Weigl JA, Schaaff F, Schmitt HJ: Are meteorological parameters associated with acute respiratory tract infections? Clin Infect Dis 2009, 49:861-868. 
20. Kurz H, Göpfrich $H$, Wabnegger L, Apfalter P: Role of chlamydophila pneumoniae in children hospitalized for community-acquired pneumonia in Vienna, Austria. Pediatr Pulmonol 2009, 44:873-876.

21. Schmidt SM, Müller CE, Krechting M, Wiersbitzky H, Gürtler L, Wiersbitzky SK: Chlamydia pneumoniae carriage and infection in hospitalized children with respiratory tract diseases. Infection 2003, 31:410-416.

22. Othman $N$, Isaacs $D$, Kesson A: Mycoplasma pneumoniae infections in Australian children. J Paediatr Child Health 2005, 41:671-676.

23. Bosnak M, Dikici B, Bosnak V, Dogru O, Ozkan I, Ceylan A, Haspolat K: Prevalence of mycoplasma pneumoniae in children in Diyarbakir, the south-east of turkey. Pediatr Int 2002, 44:510-512.

24. Higashigawa M, Kawasaki Y, Yodoya N: Prevalence of mycoplasma IgM in children with lower respiratory tract illness. Pediatr Int 2009, 51:684-686.

25. Kim NH, Lee JA, Eun BW, Shin SH, Chung EH, Park KW, Choi EH, Lee HJ: Comparison of polymerase chain reaction and the indirect particle agglutination antibody test for the diagnosis of mycoplasma pneumoniae pneumonia in children during two outbreaks. Pediatr Infect Dis J 2007, 26:897-903.

26. Maheshwari M, Kumar S, Sethi GR, Bhalla P: Detection of mycoplasma pneumoniae in children with lower respiratory tract infections. Trop Doct 2011, 41:40-42.

27. Esposito S, Blasi F, Bellini F, Allegra L, Principi N: Mycoplasma pneumoniae and Chlamydia pneumoniae infections in children with pneumonia. Eur Respir J 2001, 17:241-245.

28. Papadopoulos NG, Christodoulou I, Rohde G, Agache I, Almqvist C, Bruno A: Viruses and bacteria in acute asthma exacerbations-a GA2 LEN-DARE systematic review. Allergy 2011, 66:458-468.

29. Michelow IC, Olsen K, Lozano J, Rollins NK, Duffy LB, Ziegler T, Kauppila J, Leinonen M, McCracken GH Jr: Epidemiology and clinical characteristics of community-acquired pneumonia in hospitalized children. Pediatrics 2004, 113:701-707.

30. Stelmach I, Podsiadłowicz-Borzecka M, Grzelewski T, Majak P, Stelmach W, Jerzyńska J, Popławska M, Dziadek J: Humoral and cellular immunity in children with Mycoplasma pneumoniae infection: a 1-year prospective study. Clin Diagn Lab Immunol 2005, 12:1246-1250.

31. Tsunekawa H, Takagi E, Kishimoto H, Shimokata K: Depressed cellular immunity in Mycoplasma pneumoniae pneumonia. Eur J Respir Dis 1987, 70:293-299

32. Teig N, Anders A, Schmidt C, Rieger C, Gatermann S: Chlamydophila pneumoniae and mycoplasma pneumoniae in respiratory specimens of children with chronic lung diseases. Thorax 2005, 60:962-966.

doi:10.1186/1824-7288-39-34

Cite this article as: Chen et al.: Epidemiology and associations with climatic conditions of Mycoplasma pneumoniae and Chlamydophila pneumoniae infections among Chinese children hospitalized with acute respiratory infections. Italian Journal of Pediatrics 2013 39:34.

\section{Submit your next manuscript to BioMed Central and take full advantage of:}

- Convenient online submission

- Thorough peer review

- No space constraints or color figure charges

- Immediate publication on acceptance

- Inclusion in PubMed, CAS, Scopus and Google Scholar

- Research which is freely available for redistribution

Submit your manuscript at www.biomedcentral.com/submit
C Biomed Central 